Supporting Information for:

\title{
In Situ Formation of Unprecedented Neptunium-Oxide Wheel Clusters Stabilized in a Metal-Organic Framework
}

Sara E. Gilson, ${ }^{\dagger}$ Peng Li,,$\#$ J Jennifer E. S. Szymanowski, \acob White,\| Debmalya Ray, $\|$ Laura Gagliardi, $\|$ Omar K. Farha, ${ }^{, \pm}{ }^{\perp}$ and Peter C. Burns ${ }^{*,+, \S}$

†Department of Chemistry and Biochemistry, University of Notre Dame, Notre Dame, Indiana 46556, United States

ҒDepartment of Chemistry and Chemical and Biological Engineering, Northwestern University, 2145 Sheridan Road, Evanston, Illinois 60208, United States

§Department of Civil \& Environmental Engineering \& Earth Sciences, University of Notre Dame, Notre Dame, Indiana 46556, United States

\|Department of Chemistry, Supercomputing Institute, and Chemical Theory Center, University of Minnesota, Minneapolis, Minnesota 55455, United States

${ }^{\perp}$ Department of Chemistry, Faculty of Science, King Abdulaziz University, Jeddah 21589, Saudi Arabia 
Table of Contents:

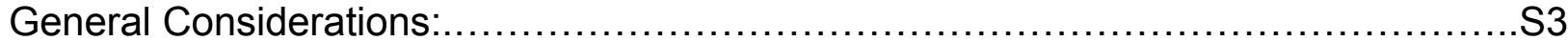

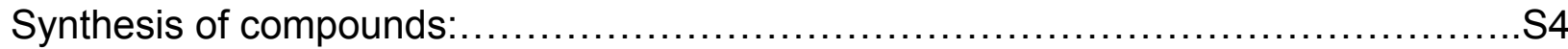

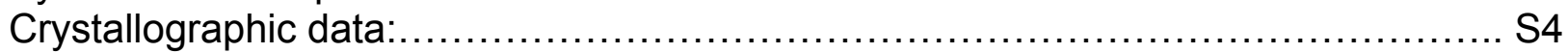

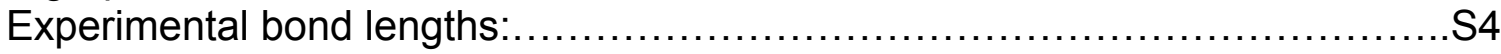

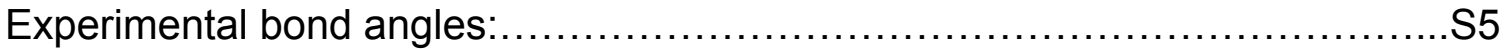

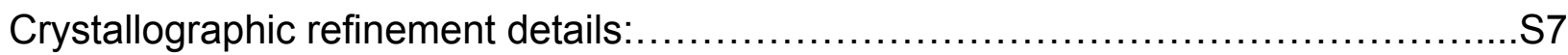

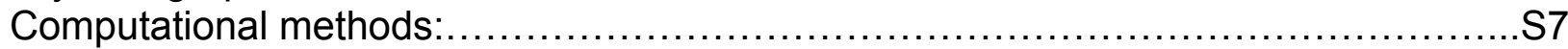

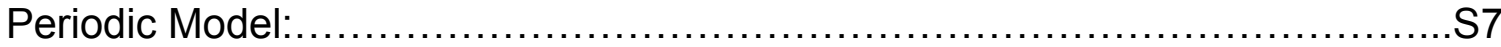

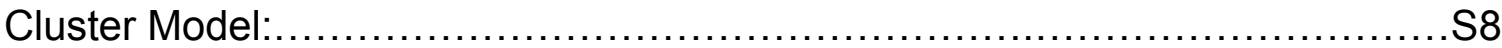

Comparison of experimental and computed crystallographic parameters:.......S8

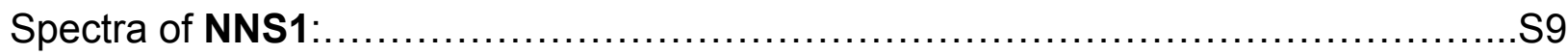

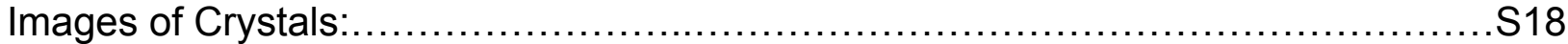

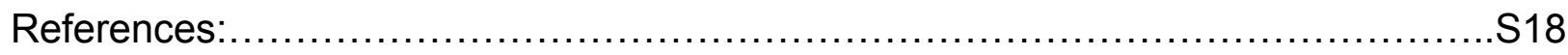




\section{General Considerations:}

Crystals of NNS1, NNS2, and NNS3 were separated from their mother liquor, coated with epoxy adhesive, and mounted on glass fibers for collection of single-crystal X-ray diffraction data. Full spheres of diffraction data were collected using a Bruker APEX-II Quazar diffractometer equipped with Mo K $\alpha$ X-ray radiation from a micro-source sealed tube. Diffraction data were collected at $298 \mathrm{~K}$ for NNS1 and at 220K for NNS2 and NNS3. Unit cell determination, data integration, and corrections for background, Lorentz, and polarization effects were performed using the Bruker APEX-II software package (SAINT). ${ }^{1-2}$ Absorption corrections were applied using the SADABS routine. ${ }^{3}$ Structure solutions were conducted using intrinsic phasing, ${ }^{4}$ and the neptunium atoms were refined anisotropically. Attempts to refine all non-hydrogen atoms anisotropically resulted in an increase of the $R_{1}$ and $w R_{2}$ values. Hydrogen atoms were fixed to their corresponding $\mathrm{C}$ atoms using a riding model. Hydrogen atoms of water molecules were

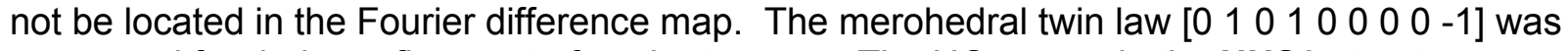
accounted for during refinement of each structure. The $\mathrm{NO}_{2}$ group in the NNS3 structure was not fully resolved. Refinement was done with the Bruker SHELXTL software package. ${ }^{5}$ Graphics were generated using the CrystalMaker software package. ${ }^{6}$ Topologies were determined through submission of crystallographic data to the ToposPro team. ${ }^{7}$ The SQUEEZE method in PLATON ${ }^{8}$ was used to correct for disordered solvent molecules in NNS2 but not NNS1 and NNS3 as this resulted in an increase of the residual values.

Crystals of NNS1 were mounted on a glass fiber with epoxy. The powder pattern was collected using a Bruker APEX-II Quazar diffractometer equipped with Mo K $\alpha$ X-ray radiation from a micro-source sealed tube. Data were collected at $298 \mathrm{~K}$ at a detector distance of $200 \mathrm{~mm}$. Debye rings were integrated over a range of 1 to $50^{\circ} 2 \theta$ with a $0.01^{\circ}$ step and a region height of 500 .

An infrared spectrum of crystals of NNS1 was obtained using a Bruker LUMOS spectrometer equipped with an 8x-Schwarzschild objective with an integrated ATR unit and a liquid nitrogencooled PermaVac mercury cadmium telluride (MCT) detector. Crystals were mounted on a glass microscope slide in Infineum oil. Spectra were obtained by crushing the crystals with a diamond-attenuated total reflectance (ATR) objective at room temperature over the range of 600 to $4000 \mathrm{~cm}^{-1}$ using 128 scans.

A Raman spectrum was collected on a single crystal of NNS1 that was secured on a glass microscope slide using carbon tape. A spectrum was acquired using a Renishaw inVia Raman Spectrometer equipped with a thermoelectrically cooled CCD detector and a $785 \mathrm{~nm}$ excitation source. The sample was scanned over 100 to $3200 \mathrm{~cm}^{-1}$ using five 10 second exposure times and $0.1 \%$ of the $300 \mathrm{~mW}$ laser power. Cosmic ray removal was applied during spectral acquisition.

Crystals of NNS1 were ground to a powder and transferred to an alumina crucible which was loaded onto a TA Instruments Q50 TGA instrument. The sample was heated to $900{ }^{\circ} \mathrm{C}$ at a rate of $5{ }^{\circ} \mathrm{C}$ under flowing high-purity nitrogen gas.

An electronic spectrum was obtained for a crystalline sample of NNS1 at room temperature using a Craic Technologies UV-Vis-NIR (NIR) microspectrophotometer. Crystals were secured in a cavity well glass microscope slide in Infineum oil. The data were collected over a range of 200 to 1700 nanometers. 
Electron microprobe analysis of NNS1 was conducted using a Cameca SX-50 instrument operating with an accelerating voltage of $15 \mathrm{kV}$ and equipped with penta-erythritol (PET) and thallium-acid phthalate (TAP) crystals. A chloroapatite standard was used to detect the presence of chlorine, using a laser with a beam current of $25 \mathrm{nAmps}$. A calcium fluoride sample was used as a standard for fluorine, with a beam current of $50 \mathrm{nAmps}$. $30 \mathrm{~s}$ counts were used for all peaks.

\section{Synthesis of compounds:}

$\mathrm{N}, \mathrm{N}$-dimethylformamide (DMF) (BDH) and trifluoroacetic acid (TFA) (Alfa Aesar) were used as received. $\left(\mathrm{NpO}_{2}\right)^{+}$was recovered from previous experiments and purified. Dissolution of $\left(\mathrm{NpO}_{2}\right)^{+}$in $1 \mathrm{M} \mathrm{HCl}$ gave $100 \mathrm{mM} \mathrm{Np}(\mathrm{V})$ in $1 \mathrm{M} \mathrm{HCl}$ stock solution. Then, approximately $1 \mathrm{~mL}$ of the $100 \mathrm{mM} \mathrm{Np}(\mathrm{V})$ in $1 \mathrm{M} \mathrm{HCl}$ stock solution was reduced to dryness on a hot plate, followed by three rinses with ultrapure water. The solid neptunium was then suspended in DMF to give a $10 \mathrm{mg} / \mathrm{mL}$ solution. UV-Vis-NIR taken of the Np in DMF stock solution indicated neptunium in the tetravalent, pentavalent, and hexavalent oxidation states.

In a $5 \mathrm{~mL}$ Savillex FEP Teflon vial, $500 \mu \mathrm{L}$ of a $10 \mathrm{mg} / \mathrm{mL} \mathrm{Np}(5.0 \mathrm{mg})$ in dimethylformamide (DMF) solution, $250 \mu \mathrm{L}$ of $2.5 \mathrm{~g} / \mathrm{L}$ ligand solution $(0.625 \mathrm{mg})$ (1,2,4,5-tetrakis(4-carboxyphenyl) benzene in DMF for NNS1, 1,4-dibromo-2,3,5,6-tetrakis(4-carboxyphenyl)benzene in DMF for NNS2, and 1-nitro-2,3,5,6-tetrakis(4-carboxyphenyl) benzene in DMF for NNS3) and $80 \mu \mathrm{L}$ of trifluoroacetic acid (TFA) were each pipetted. Vials were then sealed, stacked in a Parr reaction vessel, and heated in an oven at $130^{\circ} \mathrm{C}$ for 72 hours. Crystals were pipetted from an emerald green mother liquor, indicating the presence of neptunium remaining in solution. Experimental yields were not determined as solid-state transuranic materials pose a significant health risk to workers and measuring yield would require significant handling.

\section{Crystallographic Data:}

Table S1. Experimental bond lengths of NNS1

\begin{tabular}{|l|l|l|l|}
\hline Atom 1 & Atom 2 & Bond Length $(\AA)$ & \\
\hline Np1 & F1/OH1 & $2.358(12)$ & \\
\hline Np1 & O1 & $2.36(3)$ & \\
\hline Np1 & O4 & $1.831(18)$ & \\
\hline Np1 & O7 & $2.53(3)$ & \\
\hline Np1 & O4_a & $2.47(3)$ & \\
\hline Np1 & O6_e & $2.57(2)$ & \\
\hline Np1 & O3_j & $1.868(18)$ & \\
\hline Np2 & O3 & $2.42(2)$ & \\
\hline Np2 & $\mathrm{O} 5$ & $1.77(3)$ & \\
\hline Np2 & $\mathrm{O} 6$ & $1.94(2)$ & \\
\hline Np2 & $\mathrm{O} 8$ & $2.47(5)$ & \\
\hline Np2 & $\mathrm{O} 2 a$ & $2.47(2)$ & \\
\hline Np2 & $\mathrm{O} 3 \_j$ & $2.42(2)$ & \\
\hline Np2 & $\mathrm{O} 2 k$ & $2.47(3)$ & \\
\hline $\mathrm{O} 1$ & $\mathrm{C} 1$ & $1.20(4)$ & \\
\hline $\mathrm{O} 2$ & $\mathrm{C} 1$ & $1.20(4)$ & \\
\hline
\end{tabular}




\begin{tabular}{|l|l|l|l|}
\hline C1 & C2 & $1.54(4)$ & \\
\hline C2 & C3 & $1.35(5)$ & \\
\hline C2 & C7 & $1.35(5)$ & \\
\hline C3 & C4 & $1.38(5)$ & \\
\hline C4 & C5 & $1.41(6)$ & \\
\hline C5 & C6 & $1.30(5)$ & \\
\hline C5 & C8 & $1.56(4)$ & \\
\hline C6 & C7 & $1.34(5)$ & \\
\hline C8 & C9 & $1.39(3)$ & \\
\hline C8 & C8_C & $1.28(4)$ & \\
\hline C3 & H3A & 0.9300 & \\
\hline C4 & H4A & 0.9400 & \\
\hline C6 & H6A & 0.9300 & \\
\hline C7 & H7A & 0.9300 & \\
\hline C9 & H9A & 0.9400 & \\
\hline
\end{tabular}

Table S2. Experimental bond angles of NNS1

\begin{tabular}{|c|c|}
\hline Atom 1-Atom 2- Atom 3 & \begin{tabular}{|l|l|} 
Bond Angle $\left({ }^{\circ}\right)$ \\
\end{tabular} \\
\hline $\begin{array}{lll}\mathrm{F} 1 / \mathrm{OH} 1 & -\mathrm{Np} 1 & -\mathrm{O} 1 \\
\end{array}$ & $139.8(8)$ \\
\hline $\mathrm{F} 1 / \mathrm{OH} 1 \quad-\mathrm{Np} 1 \quad-\mathrm{O} 4$ & $88.7(8)$ \\
\hline $\begin{array}{lll}\mathrm{F} 1 / \mathrm{OH} 1 & -\mathrm{Np} 1 & -\mathrm{O} 7 \\
\end{array}$ & $144.0(9)$ \\
\hline $\begin{array}{lll}\text { F1/OH1 } & -\mathrm{Np} 1 & -\mathrm{O} 4 \_a \\
\end{array}$ & $73.5(7)$ \\
\hline F1/OH1 $-\mathrm{Np1}$-O6_e & $65.9(8)$ \\
\hline F1/OH1 $-\mathrm{Np1}$ & $89.6(8)$ \\
\hline $\mathrm{O} 1 \mathrm{-Np1}-\mathrm{O} 4$ & 92.5(9) \\
\hline $\begin{array}{lll}01 & -\mathrm{Np} 1 & -\mathrm{O} 7\end{array}$ & $76.2(8)$ \\
\hline O1 $-\mathrm{Np1}$-O4_a & $146.7(7)$ \\
\hline O1 -Np1 -O6_e & $73.9(8)$ \\
\hline 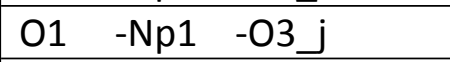 & $89.1(8)$ \\
\hline 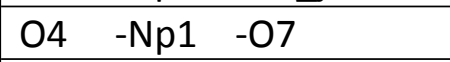 & 91.4(8) \\
\hline $\begin{array}{|lll|}\text { O4 } & -\mathrm{Np} 1 & -\mathrm{O} 4 \_\mathrm{a} \\
\end{array}$ & $90.3(8)$ \\
\hline $\begin{array}{lll}\text { O4 } & -\mathrm{Np} 1 & -\mathrm{O} 6{ }_{-} \mathrm{e} \\
\end{array}$ & $90.8(9)$ \\
\hline $\begin{array}{lll}\mathrm{O} & -\mathrm{Np} 1 & -\mathrm{O} \\
\end{array}$ & $178.3(8)$ \\
\hline O4_a $-\mathrm{Np1} \quad-\mathrm{O} 7$ & $70.6(8)$ \\
\hline O6_e - -Np1 -07 & 150.1(9) \\
\hline O3_ $-\mathrm{Np1}-\mathrm{O}$ & $89.7(8)$ \\
\hline O4_a -Np1 -O6_e & $139.3(7)$ \\
\hline O3_j -Np1 -O4_a & $88.8(8)$ \\
\hline O3_-Np1 -06_e & $88.9(9)$ \\
\hline $03-\mathrm{Np2}-05$ & $88.2(10)$ \\
\hline 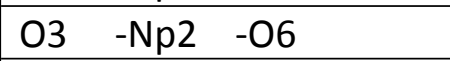 & $88.3(8)$ \\
\hline $\begin{array}{lll}\mathrm{O} 3 & -\mathrm{Np} 2 & -08 \\
\end{array}$ & $142.5(5)$ \\
\hline
\end{tabular}




\begin{tabular}{|c|c|}
\hline O2_a $-\mathrm{Np} 2 \quad-\mathrm{O} 3$ & 144.1(10) \\
\hline O3 & $72.9(6)$ \\
\hline $\mathrm{O} 2 \_\mathrm{k}-\mathrm{Np2}-\mathrm{O} 3$ & $72.2(9)$ \\
\hline O5 & $175.6(14)$ \\
\hline $\mathrm{C} 2 \quad-\mathrm{C} 3 \quad-\mathrm{C} 4$ & 119(4) \\
\hline $\begin{array}{lll}\mathrm{C} 3 & -\mathrm{C} 4 & -\mathrm{C} 5 \\
\end{array}$ & $120(4)$ \\
\hline $\mathrm{C} 4 \quad-\mathrm{C} 5 \quad-\mathrm{C} 6$ & 120(3) \\
\hline $\begin{array}{lll}\mathrm{C} 4 & -\mathrm{C} 5 & -\mathrm{C} 8\end{array}$ & $117(3)$ \\
\hline $\begin{array}{lll}\mathrm{C} 6 & -\mathrm{C} 5 & -\mathrm{C} 8\end{array}$ & $124(3)$ \\
\hline $\begin{array}{lll}\mathrm{C} 5 & -\mathrm{C} 6 & -\mathrm{C} 7\end{array}$ & $120(4)$ \\
\hline $\begin{array}{lll}\mathrm{C} 2 & -\mathrm{C} 7 & -\mathrm{C} 6\end{array}$ & $123(4)$ \\
\hline 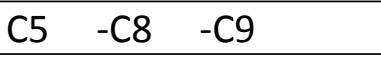 & $118(3)$ \\
\hline C5 $-\mathrm{C} 8 \mathrm{-C} 8 \mathrm{C}_{-} \mathrm{c}$ & $122(3)$ \\
\hline C8_c $-\mathrm{C} 8 \mathrm{-C}$ & $120(3)$ \\
\hline O5 $\quad-\mathrm{Np} 2 \quad-\mathrm{O} 8$ & $101.5(14)$ \\
\hline O2_a $-\mathrm{Np} 2 \quad-\mathrm{O} 5$ & $82.3(7)$ \\
\hline $\mathrm{O} 3 \_-\mathrm{Np2} \quad-\mathrm{O} 5$ & $88.2(10)$ \\
\hline O2_k $-\mathrm{Np} 2-05$ & $82.3(7)$ \\
\hline $06-\mathrm{Np2} \quad-08$ & $82.9(12)$ \\
\hline O2_a - -Np2 -06 & $99.0(7)$ \\
\hline O3_j $-\mathrm{Np2}-\mathrm{O} 6$ & $88.3(8)$ \\
\hline O2_k - $-\mathrm{Np} 2-\mathrm{O} 6$ & 99.0(7) \\
\hline $\begin{array}{lll}\mathrm{O} 2 \_a & -\mathrm{Np} 2 & -\mathrm{O} 8\end{array}$ & 73.4(9) \\
\hline $03 \_-N p 2 \quad-08$ & $142.5(5)$ \\
\hline O2_k $-\mathrm{Np2}-\mathrm{O} 8$ & 73.4(9) \\
\hline O2_a & $72.2(9)$ \\
\hline $\mathrm{O} 2 \_\mathrm{a}-\mathrm{Np} 2-\mathrm{O} 2 \_\mathrm{k}$ & $139.6(10)$ \\
\hline O2_k $-\mathrm{Np} 2 \quad-03$ & $144.1(10)$ \\
\hline Np1 & 114.2(9) \\
\hline $\begin{array}{lll}\text { Np1 } & -01 & -\mathrm{C} 1\end{array}$ & $157(2)$ \\
\hline Np2_e - O2 $-\mathrm{C} 1$ & $124(2)$ \\
\hline Np1_j- $-\mathrm{O} 3 \quad-\mathrm{Np} 2$ & $142.9(9)$ \\
\hline Np1 -O4 -Np1_e & $142.4(10)$ \\
\hline Np1_a $-06 \quad-N p 2$ & $129.6(4)$ \\
\hline Np1_k $-06 \quad-N p 2$ & \begin{tabular}{|l}
$129.6(4)$ \\
\end{tabular} \\
\hline Np1_a -O6 -Np1_k & \begin{tabular}{|l|}
$100.7(8)$ \\
\end{tabular} \\
\hline $\mathrm{O} 1 \mathrm{-C} 1 \mathrm{-O} 2$ & $122(3)$ \\
\hline $\mathrm{O} 1 \quad-\mathrm{C} 1 \quad-\mathrm{C} 2$ & $121(3)$ \\
\hline $\mathrm{O} 2-\mathrm{C} 1 \quad-\mathrm{C} 2$ & $117(3)$ \\
\hline 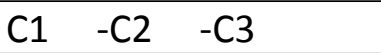 & $117(3)$ \\
\hline $\begin{array}{lll}\mathrm{C} 1 & -\mathrm{C} 2 & -\mathrm{C} 7\end{array}$ & $124(3)$ \\
\hline $\begin{array}{lll}\mathrm{C} 3 & -\mathrm{C} 2 & -\mathrm{C} 7\end{array}$ & 119(3) \\
\hline
\end{tabular}




\begin{tabular}{|lll|l|}
\hline $\mathrm{C} 2$ & $-\mathrm{C} 3$ & $-\mathrm{H} 3 \mathrm{~A}$ & 120.00 \\
\hline $\mathrm{C} 4$ & $-\mathrm{C} 3$ & $-\mathrm{H} 3 \mathrm{~A}$ & 121.00 \\
\hline $\mathrm{C} 3$ & $-\mathrm{C} 4$ & $-\mathrm{H} 4 \mathrm{~A}$ & 120.00 \\
\hline $\mathrm{C} 5$ & $-\mathrm{C} 4$ & $-\mathrm{H} 4 \mathrm{~A}$ & 120.00 \\
\hline $\mathrm{C} 5$ & $-\mathrm{C} 6$ & $-\mathrm{H} 6 \mathrm{~A}$ & 120.00 \\
\hline $\mathrm{C} 7$ & $-\mathrm{C} 6$ & $-\mathrm{H} 6 \mathrm{~A}$ & 120.00 \\
\hline $\mathrm{C} 2$ & $-\mathrm{C} 7$ & $-\mathrm{H} 7 \mathrm{~A}$ & 119.00 \\
\hline $\mathrm{C} 6$ & $-\mathrm{C} 7$ & $-\mathrm{H} 7 \mathrm{~A}$ & 118.00 \\
\hline $\mathrm{C} 8$ & $-\mathrm{C} 9$ & $-\mathrm{H} 9 \mathrm{~A}$ & 120.00 \\
\hline $\mathrm{C} 8-\mathrm{i}$ & $-\mathrm{C} 9$ & $-\mathrm{H} 9 \mathrm{~A}$ & 120.00 \\
\hline $\mathrm{C} 8$ & $-\mathrm{C} 9$ & $-\mathrm{C} 8 \_\mathrm{i}$ & $121(3)$ \\
\hline
\end{tabular}

Table S3. Crystal data and structure refinement for NNS1

\begin{tabular}{|l|l|}
\hline Chemical formula & {$\left[\mathrm{C}_{34} \mathrm{H}_{18} \mathrm{O}_{8}\right](\mathrm{F} / \mathrm{OH})_{2}\left(\mathrm{H}_{2} \mathrm{O}\right)_{6}\left(\mathrm{NpO}_{2}\right)_{6}$} \\
\hline$M_{r}$ & 733.12 \\
\hline Crystal system & Hexagonal \\
\hline Space group & $P 6 / m$ \\
\hline Temperature $(\mathrm{K})$ & 298 \\
\hline$a, c(\AA)$ & $20.915(13)$, \\
& $18.518(12)$ \\
\hline$V\left(\AA^{3}\right)$ & $7015(10)$ \\
\hline$Z$ & 3 \\
\hline$D_{x}\left(\mathrm{Mg} / \mathrm{mm}^{3)}\right.$ & 0.174 \\
\hline Radiation & $\mathrm{X}$-ray MoKa $(\lambda=0.71073)$ \\
\hline$\mu\left(\mathrm{mm}^{-1}\right)$ & 0.739 \\
\hline Crystal size $\left(\mathrm{mm}^{3}\right)$ & $0.150 \times 0.150 \times 0.050$ \\
\hline Diffractometer & Bruker APEX II Quazar \\
\hline Scan Method & $\omega-\theta-\mathrm{scans}$ \\
\hline $\begin{array}{l}\text { No. of measured, independent, and observed } \\
\text { reflections }\end{array}$ & $50793,2917,2527$ \\
\hline$R_{\text {int }}$ & \\
\hline (sin $\theta / \lambda)_{\text {max }}\left(\AA^{-1}\right)$ & 0.0457 \\
\hline$R\left[\mathrm{~F}^{2}>2 \sigma\left(\mathrm{F}^{2}\right)\right], w R\left(\mathrm{~F}^{2}\right), S$ & 0.975 \\
\hline No. of parameters & $0.069,0.19,0.94$ \\
\hline$\Delta \rho m a x, \Delta \rho m i n(e \AA-3)$ & 84 \\
\hline & $4.877,-2.532$ \\
\hline
\end{tabular}

\section{Computational Methods}

\section{Periodic Model}

We started with the experimental crystal structure of neptunium-based MOF and optimized it using the VASP package..$^{9-12}$ We used both $\mathrm{PBE}^{13}$ and PBESol ${ }^{14}$ functionals for optimizing the crystal structure. A plane-wave kinetic energy cutoff of $520 \mathrm{eV}$ was used for all the calculations. The Brillouin zone was sampled using a $1 \times 1 \times 1 \mathrm{k}$-point grid. We used $10^{-5} \mathrm{eV}$ energy convergence criteria and $0.05 \mathrm{eV} / \AA \AA$ force convergence criteria for all our calculations. 


\section{Cluster Model}

A neptunium (V) cluster was cut from the structure optimized with PBE in the periodic model, and each organic linker was replaced with formate. The cluster has the formula $(\mathrm{CHO})_{12} \mathrm{~F}_{6}\left(\mathrm{H}_{2} \mathrm{O}\right)_{18}\left(\mathrm{NpO}_{2}\right)_{18}$. This structure was used as the cluster model to obtain representative frequencies, IR intensities, and Raman intensities for the symmetric and asymmetric stretching modes of $\mathrm{NpO}_{2}{ }^{+}$in the SBUs of NNS1. In principle, this information could be obtained from the periodic calculations but at a greater computational cost due to the larger number of atoms in the periodic model.

Turbomole 7.315-16 was used for all calculations on the cluster model. The structure was optimized with the $\mathrm{PBE}^{13}$ functional. Triple zeta valence basis sets with polarization functions were used for $\mathrm{H}, \mathrm{C}, \mathrm{N}, \mathrm{O}$, and $\mathrm{F}^{17}$. The small core Wood-Boring type effective core potential for $\mathrm{Np}^{18}$ and the corresponding triple zeta quality basis set with polarization ${ }^{19}$ were used for $\mathrm{Np}$. These basis sets and the effective core potential are denoted def-TZVP and def-ecp in Turbomole 7.3. Gradients were evaluated analytically, including the derivative of the energy with respect to the quadrature weights of the numerical grid. The frequencies were computed numerically to simulate the vibrational modes and ensure that the optimized structure was at a local minimum. No imaginary frequencies were observed. Derivatives of the static polarizability were computed to model the Raman intensities using the egrad module. ${ }^{20-21}$ The resolution of identity approximation ${ }^{22-23}$ was applied to reduce the cost of the calculations. The self-consistent field convergence criteria were set to $1 \mathrm{E}-6 \mathrm{E}_{\mathrm{h}}$ for the energy and $1 \mathrm{E}-7$ for the root mean squared of the density. For the geometry optimization, the maximum norm of the gradient was converged to $1 \mathrm{E}-4$ a.u. Numerical integrations were carried out with the $\mathrm{m} 4 \mathrm{grid}^{24}$ scheme in Turbomole 7.3.

Table S4. Comparison of computed and experimental lattice parameters of NNS1

\begin{tabular}{|l|l|l|l|l|l|l|}
\hline & $\mathrm{a}(\AA)$ & $\mathrm{b}(\AA)$ & $\mathrm{c}(\AA)$ & $\mathrm{a}\left(\left(^{\circ}\right)\right.$ & $\beta\left(^{\circ}\right)$ & $\mathrm{\gamma}\left(^{\circ}\right)$ \\
\hline PBE & 20.73 & 20.70 & 18.78 & 90.3 & 90.0 & 120.0 \\
\hline PBEsol & 20.46 & 20.44 & 18.62 & 90.3 & 90.0 & 120.0 \\
\hline Experimental & $20.91(1)$ & $20.91(1)$ & $18.51(1)$ & 90.0 & 90.0 & 120.0 \\
\hline
\end{tabular}

Table S5. Comparison of computed and experimental bond lengths of the two distinct Np coordination environments of the NNS1 SBUs

\begin{tabular}{|l|l|l|l|l|}
\hline & $\begin{array}{l}\text { Turbomole } \\
\text { PBE } \\
\text { Cluster }\end{array}$ & PBE Periodic & $\begin{array}{l}\text { PBEsol } \\
\text { Periodic }\end{array}$ & Experiment \\
\hline$R(\mathrm{~Np} 1-\mathrm{O} 1)_{\mathrm{yl}}(\AA)$ & 1.88 & 1.9 & 1.9 & 1.84 \\
\hline $\mathrm{R}(\mathrm{Np} 1-\mathrm{O} 2)(\AA)$ & 1.87 & 1.88 & 1.88 & 1.89 \\
\hline $\mathrm{R}(\mathrm{Np} 1-\mathrm{O} 1)_{\mathrm{eq}}(\AA)$ & 2.39 & 2.39 & 2.33 & 2.58 \\
\hline $\mathrm{R}(\mathrm{Np} 1-\mathrm{O})(\AA)$ & 2.58 & 2.59 & 2.41 & 2.47 \\
\hline $\mathrm{R}(\mathrm{Np} 1-\mathrm{O}) \mathrm{L}(\AA)$ & 2.48 & 2.32 & 2.28 & 2.37 \\
\hline $\mathrm{R}\left(\mathrm{Np} 1-\mathrm{O}_{\mathrm{w}}\right)(\AA)$ & 2.59 & 2.64 & 2.58 & 2.54 \\
\hline $\mathrm{R}(\mathrm{Np} 1-\mathrm{F})(\AA)$ & 2.28 & 2.27 & 2.25 & 2.36 \\
\hline$R(\mathrm{~Np} 2-\mathrm{O} 4)(\AA)$ & 1.93 & 1.94 & 1.94 & 1.94 \\
\hline
\end{tabular}




\begin{tabular}{|l|l|l|l|l|}
\hline$R(N p 2-O 3)(\AA)$ & 1.8 & 1.8 & 1.79 & 1.77 \\
\hline$R(N p 2-O 2)(\AA)$ & 2.42 & 2.4 & 2.33 & 2.4 \\
\hline$R(N p 2-O) L(\AA)$ & 2.49 & 2.46 & 2.41 & 2.48 \\
\hline$R\left(N p 2-\mathrm{O}_{w}\right)(\AA)$ & 2.62 & 2.65 & 2.58 & 2.48 \\
\hline $\operatorname{TUE}^{*}(\AA)$ & 0.76 & 0.81 & 0.85 & 0.00 \\
\hline
\end{tabular}

${ }^{*}$ TUE: total unsigned error, relative to the crystal structure

\section{Spectra of NNS1}

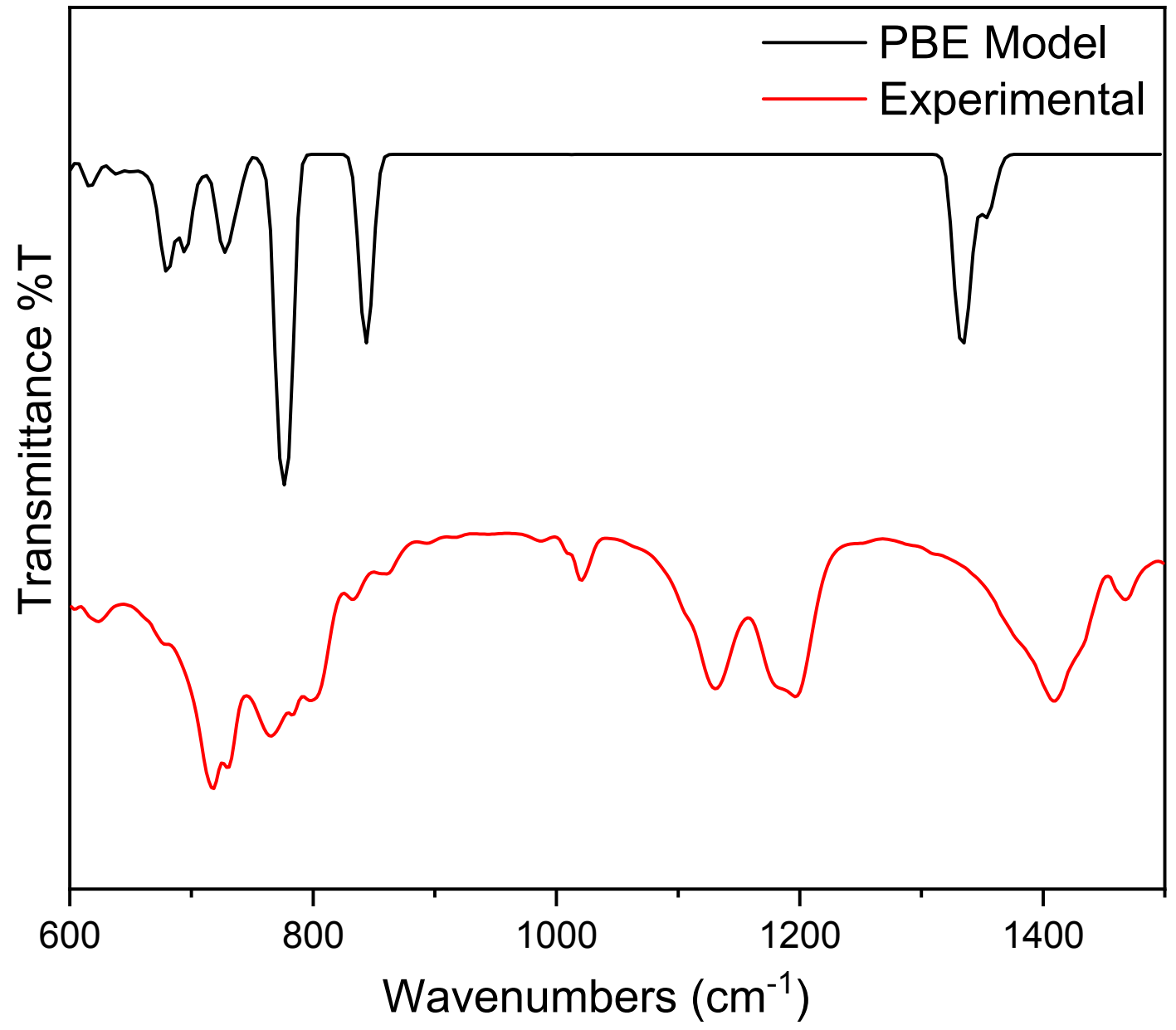

Figure S1. FT-IR spectra of NNS1. The simulated IR spectrum (PBE model) has 44 vibrational modes in the $650 \mathrm{~cm}^{-1}$ to $850 \mathrm{~cm}^{-1}$ range. Rotational modes of the coordinated water molecules with small contributions from $\mathrm{NpO}_{2}{ }^{+}$symmetric stretches are in the $650 \mathrm{~cm}^{-1}$ to $686 \mathrm{~cm}^{-1}$ range. The 5 modes in the $690-710 \mathrm{~cm}^{-1}$ range are a mixture of $\mathrm{NpO}_{2}{ }^{+}$symmetric and asymmetric stretches. 24 IR active modes were identified in the $720 \mathrm{~cm}^{-1}$ to $730 \mathrm{~cm}^{-1}$ range that are mostly formate scissoring modes with mixtures of $\mathrm{NpO}_{2}{ }^{+}$symmetric stretches and asymmetric stretches. Nearly pure formate scissoring modes occur at $738 \mathrm{~cm}^{-1} .6 \mathrm{~Np}^{-1 \mathrm{O}_{2}}{ }^{+}$asymmetric stretching modes are in the $760 \mathrm{~cm}^{-1}$ to $776 \mathrm{~cm}^{-1}$ range. The mode at $776 \mathrm{~cm}^{-1}$ is a purely asymmetric stretching mode. The other modes in this range have small contributions from $\mathrm{NpO}_{2}{ }^{+}$symmetric stretches. $6 \mathrm{~Np}_{2} \mathrm{O}_{2}{ }^{+}$asymmetric stretching modes are in the $840 \mathrm{~cm}^{-1}$ to 845 $\mathrm{cm}^{-1}$ range. Two of these modes, $843 \mathrm{~cm}^{-1}$ and $844 \mathrm{~cm}^{-1}$, are purely asymmetric modes and the others have small symmetric stretching contributions. The contributions of the various molecular 
motions to the computed IR active modes were assigned by comparing the nuclear displacement vectors of water, formate, fluorine, and neptunyl for each mode.

The computed IR active modes were compared with the experimental IR spectrum in the $650 \mathrm{~cm}^{-1}$ to $850 \mathrm{~cm}^{-1}$ range. From the cluster model calculations, asymmetric stretching modes for $\mathrm{Np}_{1} \mathrm{O}_{2}{ }^{+}$and $\mathrm{Np}_{2} \mathrm{O}_{2}{ }^{+}$can be unambiguously assigned to the peaks at $775 \mathrm{~cm}^{-1}$ and $840 \mathrm{~cm}^{-1}$ respectively. Based on these results, it is reasonable to assign the $\mathrm{Np} 1$ and Np2 asymmetric stretching modes in the experimental spectrum to the peaks at $775 \mathrm{~cm}^{-1}$ and $810 \mathrm{~cm}^{-1}$. The computed peaks at $730 \mathrm{~cm}^{-1}$ and $680 \mathrm{~cm}^{-1}$ most closely match the experimental peaks at 730 $\mathrm{cm}^{-1}$ and $675 \mathrm{~cm}^{-1}$. Both peaks have some $\mathrm{NpO}_{2}{ }^{+}$symmetric stretching character, but also have contributions from the coordinated water molecules and the model organic linker. $\mathrm{An} \mathrm{NpO}_{2}{ }^{+}$ symmetric stretch cannot be definitively assigned to the experimental spectrum based on the simulated spectrum, but it is likely that the peak at $675 \mathrm{~cm}^{-1}$ has the largest contribution from the symmetric stretches.

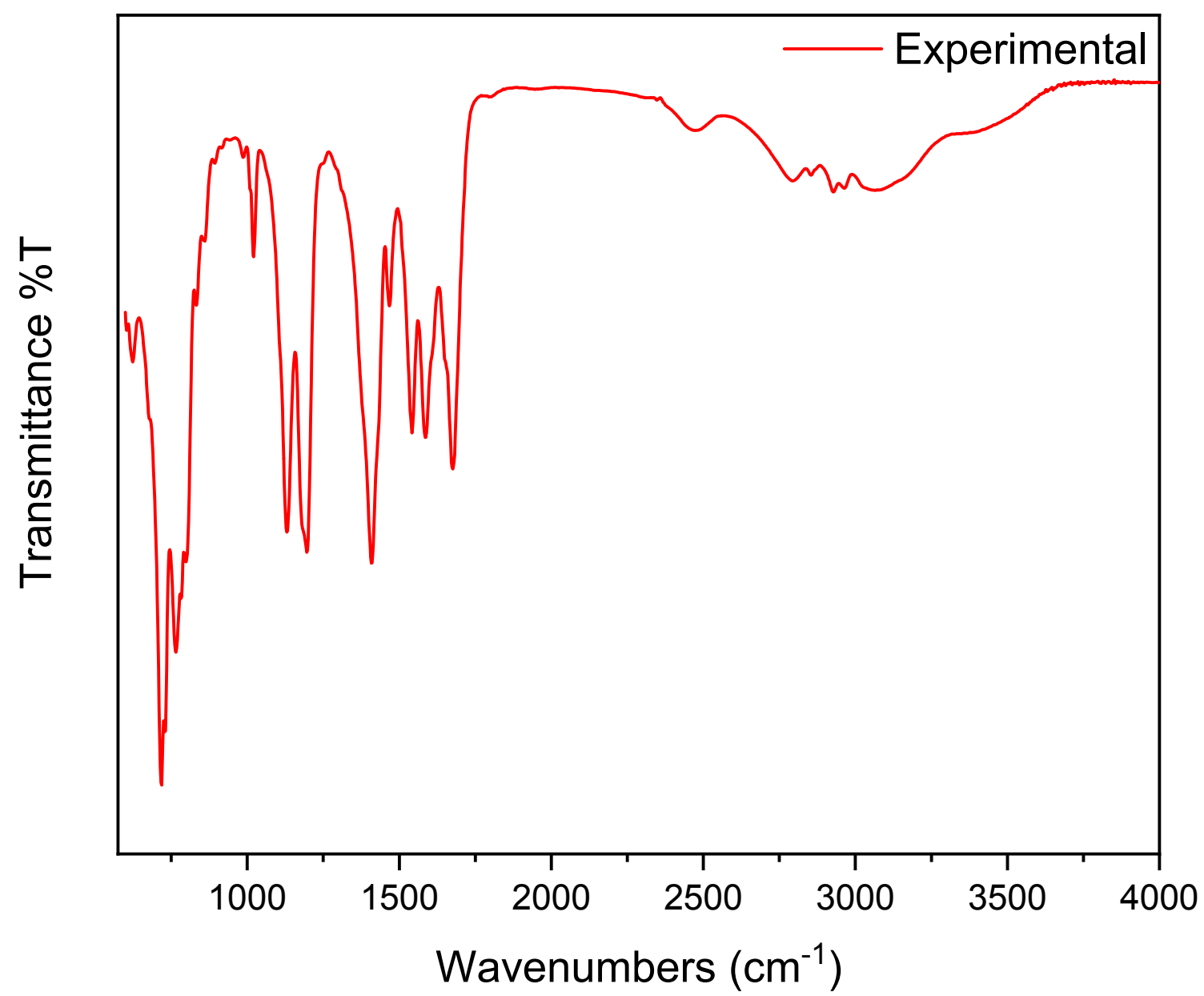

Figure S2. Complete experimental FT-IR spectrum of NNS1. 


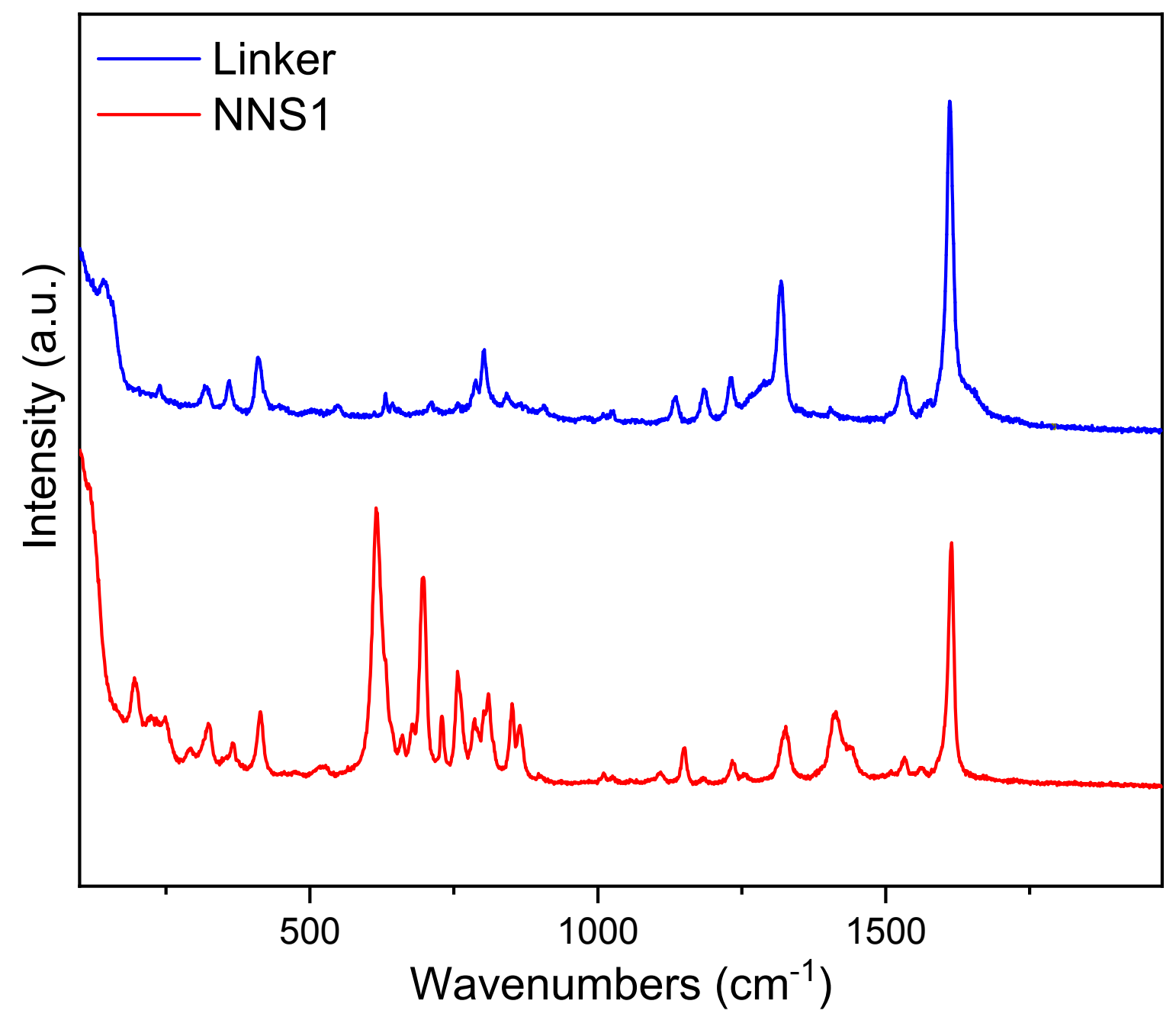

Figure S3. Experimental Raman spectra of NNS1 and the tetratopic 1,2,4,5-tetrakis(4carboxyphenyl)benzene linker. 


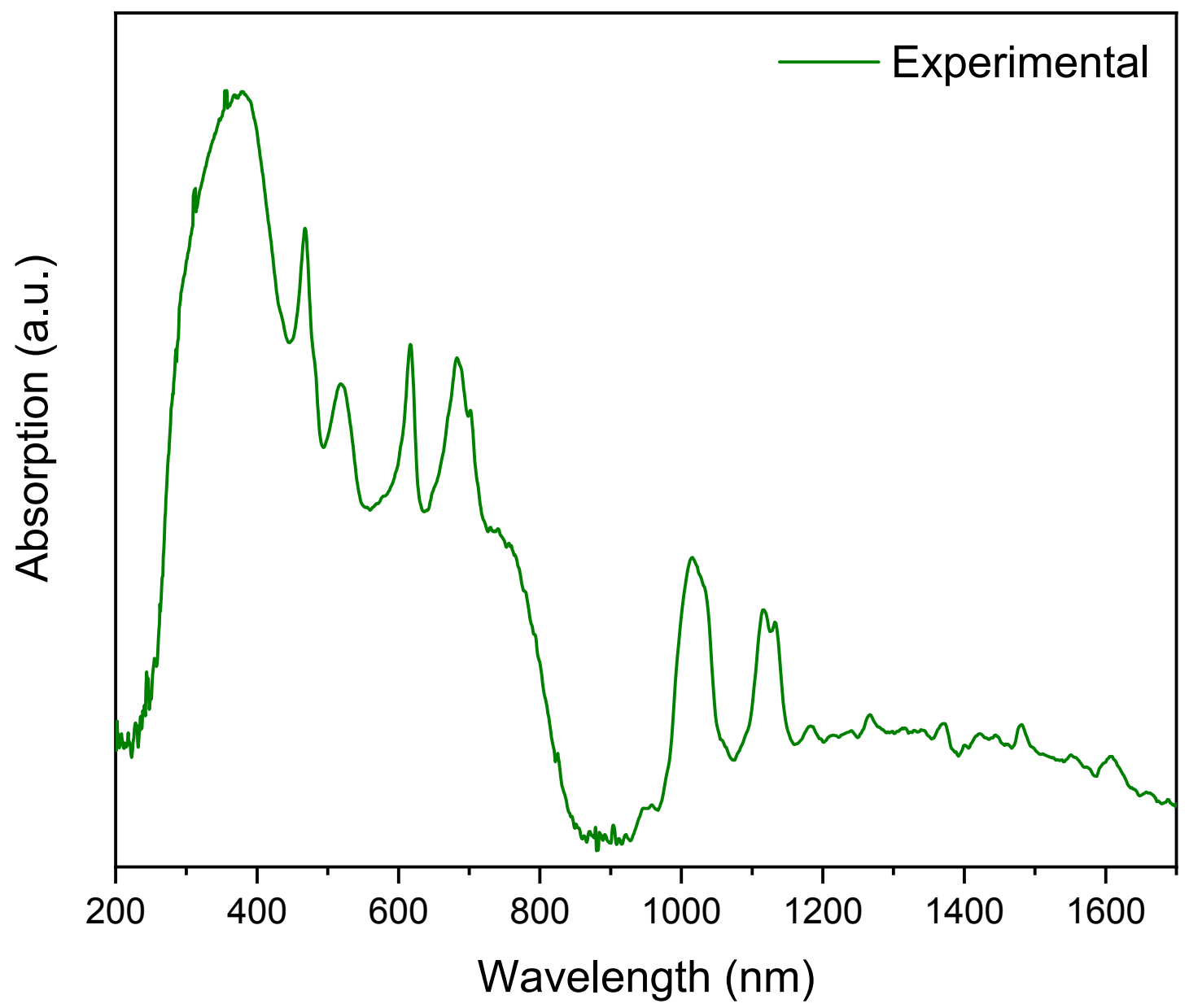

Figure S4. Experimental UV-Vis-NIR spectrum of NNS1. The peak located at approximately $1026 \mathrm{~nm}$ is characteristic of the $\mathrm{Np}(\mathrm{V}) \mathrm{O}_{2}{ }^{+}$cation. Peaks in the near-IR region are $\mathrm{f}-\mathrm{f}$ transitions typical of $\mathrm{Np}(\mathrm{V})$-containing compounds. ${ }^{25-26}$ 


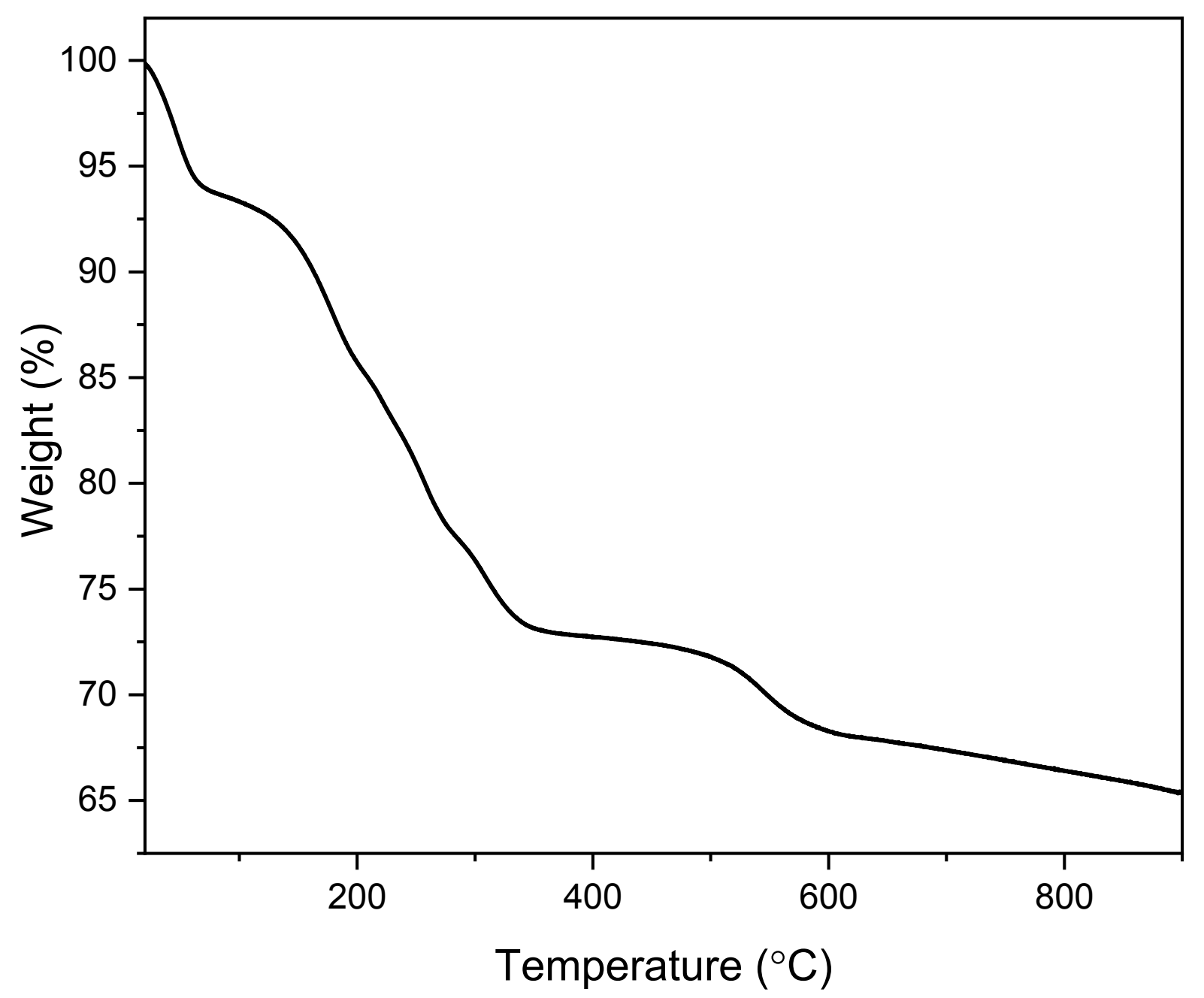

Figure S5. Experimental TGA of NNS1. For the formula $\left[\mathrm{C}_{34} \mathrm{O}_{8} \mathrm{H}_{18}\right]_{3}(\mathrm{~F} / \mathrm{OH})_{6}\left(\mathrm{H}_{2} \mathrm{O}\right)_{18}\left(\mathrm{NpO}_{2}\right)_{18}$ conversion to $\mathrm{NpO}_{2}$ (as shown by the powder X-ray diffraction data in Figure S6) would result in loss of $30.2 \%$ of the weight. The organic linkers correspond to $23.9 \%$, the $\mathrm{H}_{2} \mathrm{O}$ to $4.7 \%$, and the $\mathrm{F} / \mathrm{OH}$ to $1.6 \%$. The mass loss during TGA was approximately $34 \%$, with guest molecules likely accounting for the difference. 


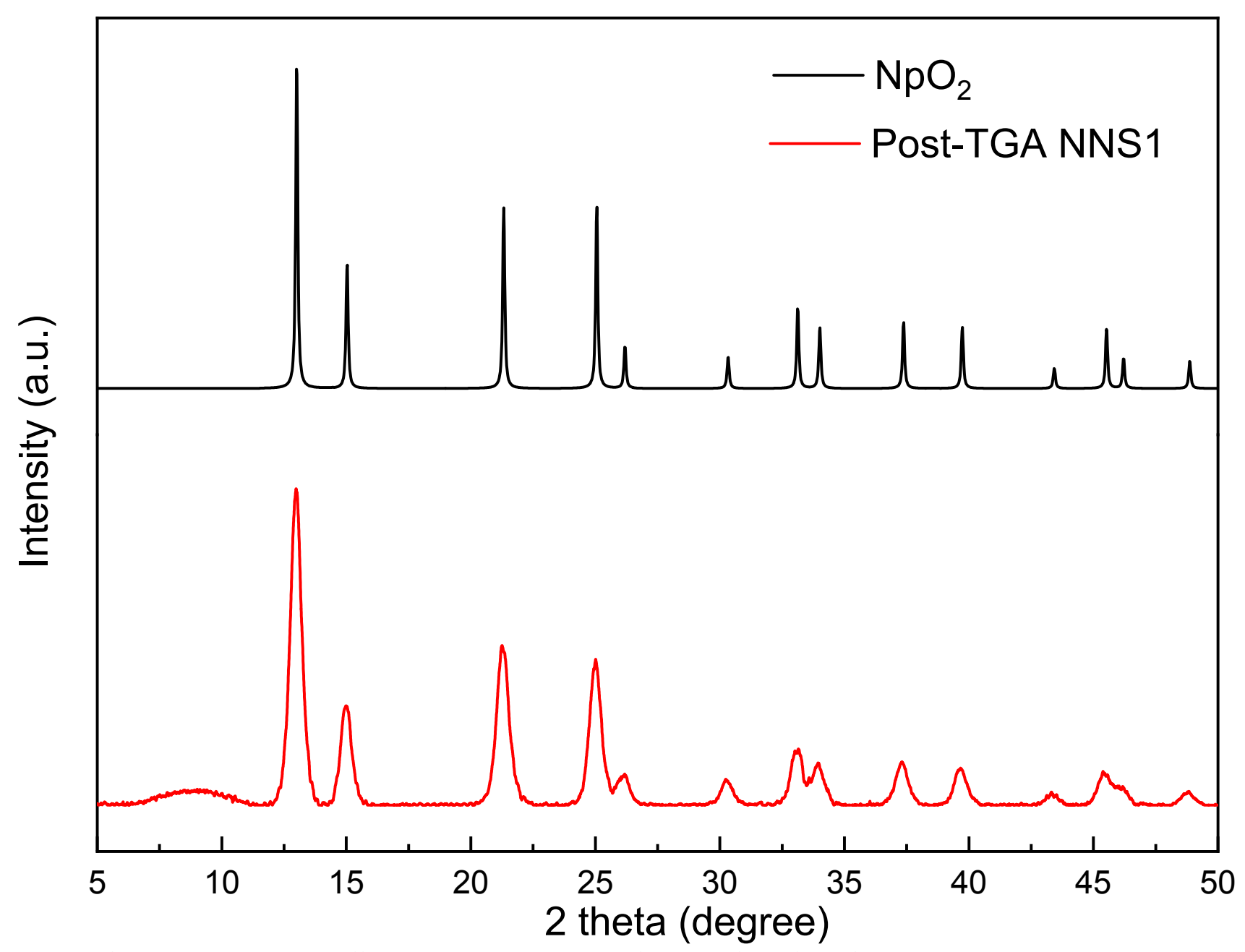

Figure S6. Powder X-ray diffraction data (PXRD) of post-TGA of NNS1. 


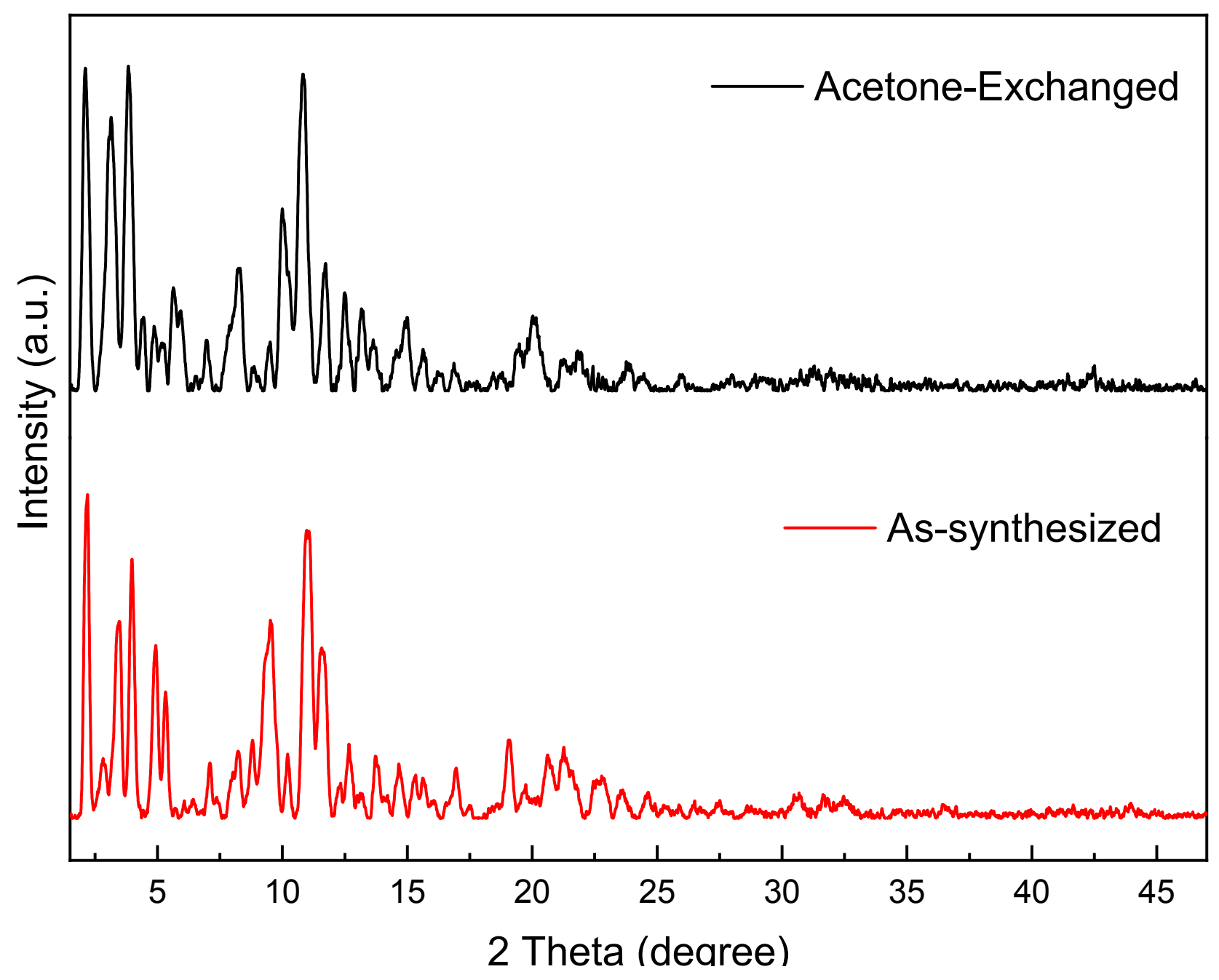

Figure S7. Powder X-ray diffraction data (PXRD) of as-synthesized and acetone-exchanged NNS1. 


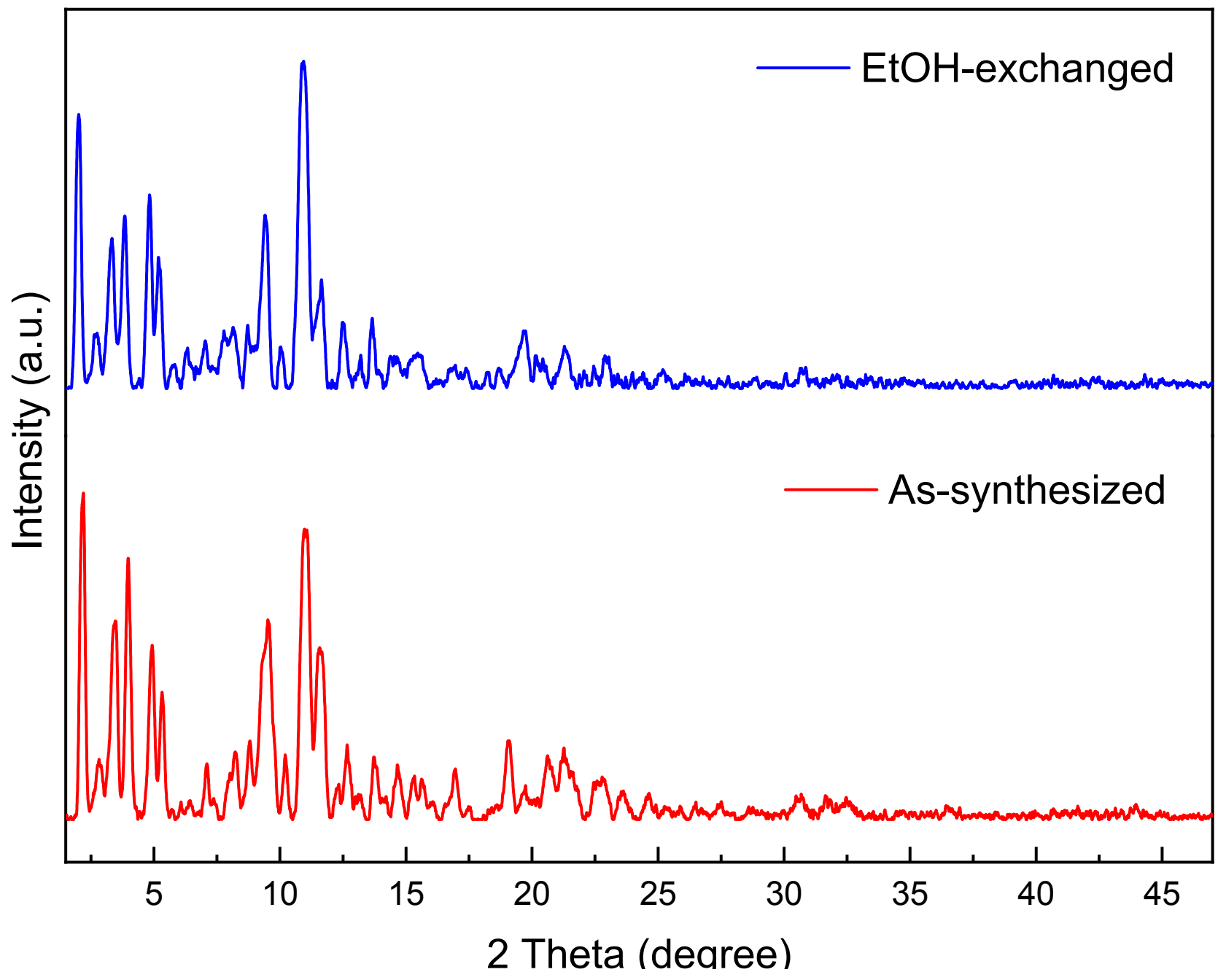

Figure S8. Powder X-ray diffraction data (PXRD) of as-synthesized and ethanol-exchanged NNS1. 


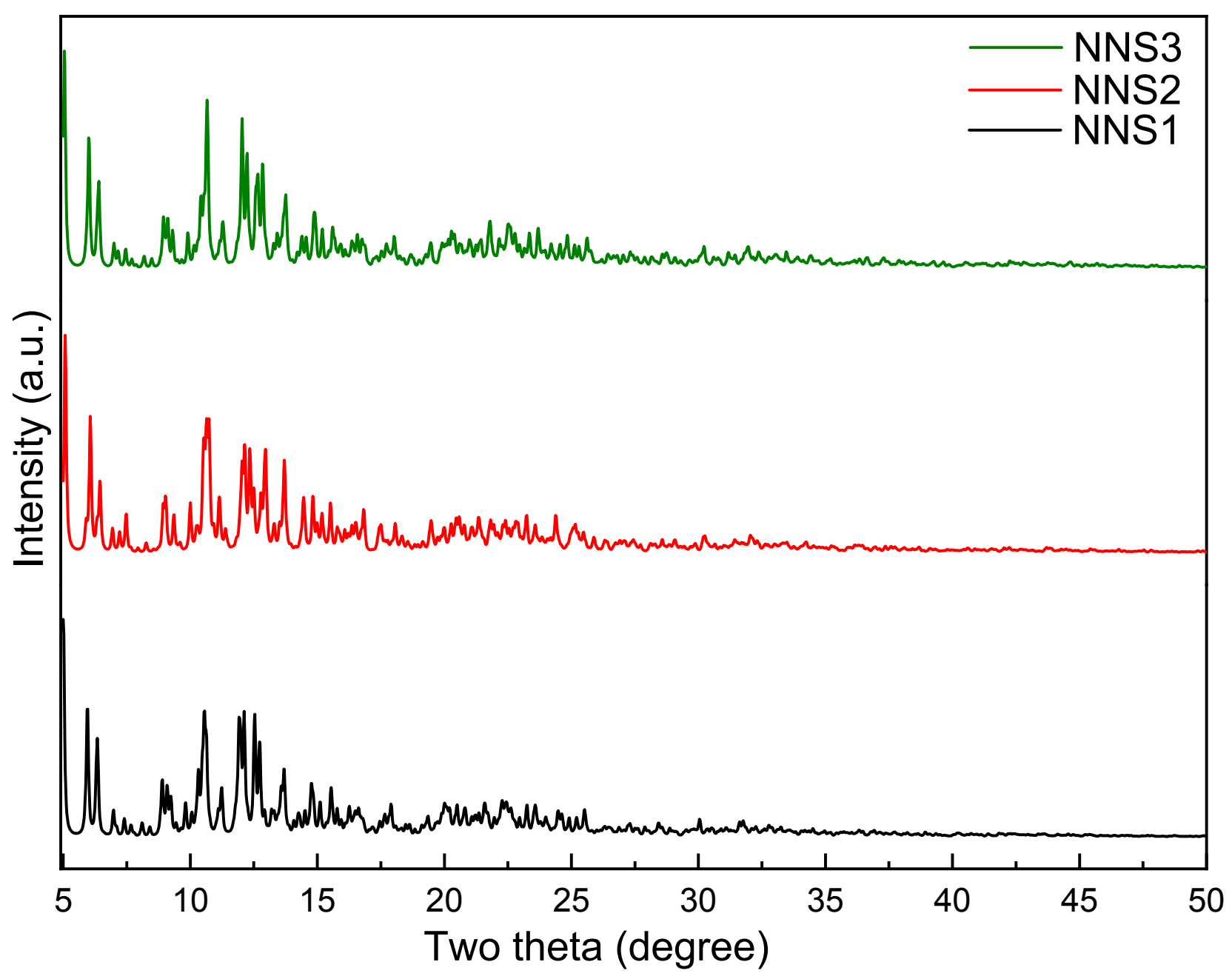

Figure S9. Powder X-ray diffraction data (PXRD) of NNS1, NNS2, and NNS3 as simulated from crystallographic data. 

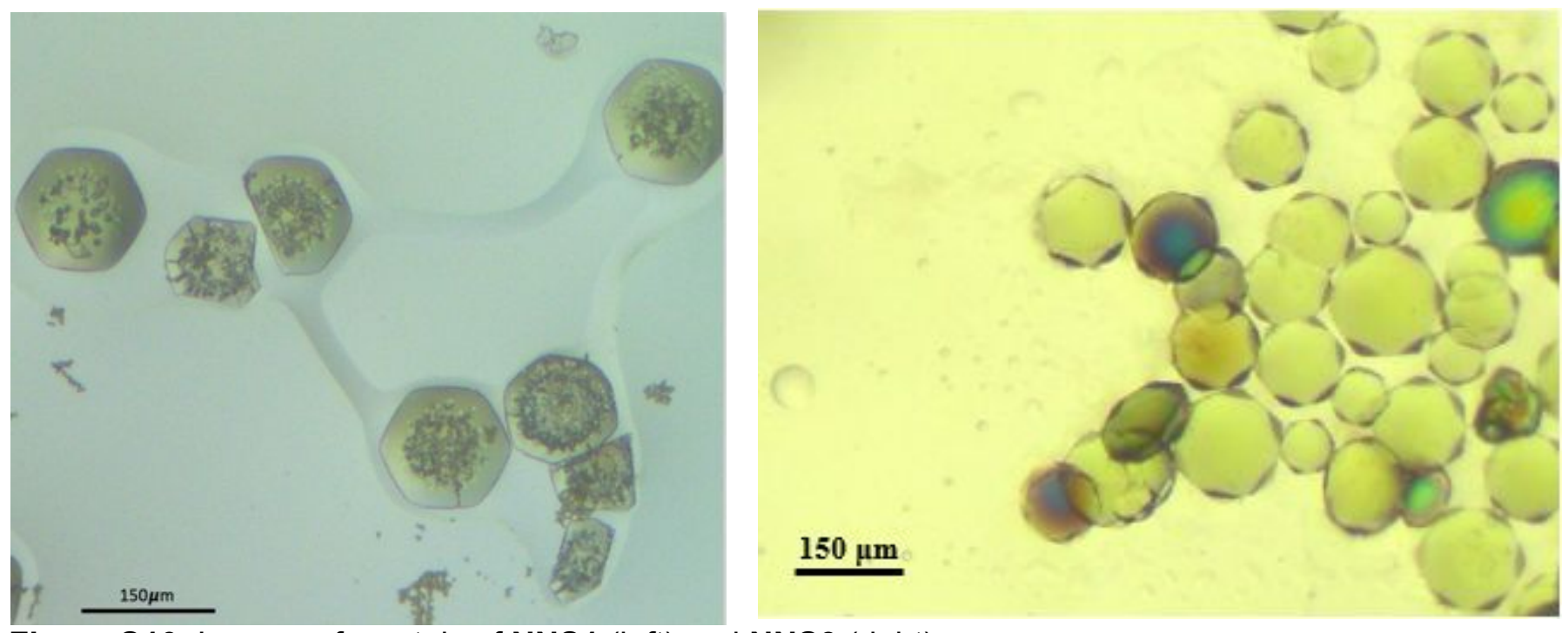

Figure S10. Images of crystals of NNS1 (left) and NNS3 (right)

\section{References:}

(1) APEX 3, Madison WI, 2016.

(2) SAINT V.8.34A, Madison WI, 2014.

(3) SADABS, Madison, WI, 2016.

(4) Sheldrick, G. M. SHELXT, University of Gottingen, 2013.

(5) Sheldrick, G. M. SHELXL, University of Gottingen, 2014.

(6) CrystalMaker V.10.3.1, CrystalMaker Software, 2018.

(7) Blatov, V. A. TOPOS, Samara State University, Russia., 2004.

(8) Spek, A., PLATON SQUEEZE: a tool for the calculation of the disordered solvent contribution to the calculated structure factors. Acta Crystallogr., Sect. C: Cryst. Struct. Commun. 2015, 71, 9-18.

(9) Kresse, G.; Hafner, J., Ab initio molecular-dynamics simulation of the liquid-metal-amorphous-semiconductor transition in germanium. Phys. Rev. B: Condens. Matter Mater. Phys. 1994, 49, 14251-14269.

(10) Kresse, G.; Furthmüller, J., Efficient iterative schemes for ab initio total-energy calculations using a plane-wave basis set. Phys. Rev. B: Condens. Matter Mater. Phys. 1996, 54, 1116911186.

(11) Kresse, G.; Hafner, J., Ab initio molecular dynamics for liquid metals. Phys. Rev. B: Condens. Matter Mater. Phys. 1993, 47, 558-561.

(12) Kresse, G.; Furthmüller, J., Efficiency of ab-initio total energy calculations for metals and semiconductors using a plane-wave basis set. Computational Materials Science 1996, 6, 15-50. (13) Perdew, J. P.; Wang, Y., Accurate and simple analytic representation of the electron-gas correlation energy. Phys. Rev. B: Condens. Matter Mater. Phys. 1992, 45, 13244-13249.

(14) Perdew, J. P.; Ruzsinszky, A.; Csonka, G. I.; Vydrov, O. A.; Scuseria, G. E.; Constantin, L. A.; Zhou, X.; Burke, K., Restoring the Density-Gradient Expansion for Exchange in Solids and Surfaces. Phys. Rev. Lett. 2008, 100, 136406.

(15) Turbomole V7.3 2018, a Development of University of Karlsruhe and Forschungszentrum Karlsruhe $\mathrm{GmbH}$,. 1989-2007, TURBOMOLE GmbH, since 2007. available from http://www.turbomole.com. 
(16) Steffen, C.; Thomas, K.; Huniar, U.; Hellweg, A.; Rubner, O.; Schroer, A., TmoleX-A graphical user interface for TURBOMOLE. J. Comput. Chem. 2010, 31, 2967-2970.

(17) Schäfer, A.; Horn, H.; Ahlrichs, R., Fully optimized contracted Gaussian basis sets for atoms Li to Kr. J. Chem. Phys. 1992, 97, 2571-2577.

(18) Küchle, W.; Dolg, M.; Stoll, H.; Preuss, H., Energy-adjusted pseudopotentials for the actinides. Parameter sets and test calculations for thorium and thorium monoxide. J. Chem. Phys. 1994, 100, 7535-7542.

(19) Cao, X.; Dolg, M.; Stoll, H., Valence basis sets for relativistic energy-consistent small-core actinide pseudopotentials. J. Chem. Phys. 2003, 118, 487-496.

(20) Rappoport, D.; Furche, F., Lagrangian approach to molecular vibrational Raman intensities using time-dependent hybrid density functional theory. J. Chem. Phys. 2007, 126, 201104.

(21) Rappoport, D.; Furche, F., Analytical time-dependent density functional derivative methods within the RI-J approximation, an approach to excited states of large molecules. J. Chem. Phys. 2005, 122, 064105.

(22) Eichkorn, K.; Treutler, O.; Öhm, H.; Häser, M.; Ahlrichs, R., Auxiliary basis sets to approximate Coulomb potentials. Chem. Phys. Lett. 1995, 240, 283-290.

(23) Eichkorn, K.; Htiser, M.; Ahlrichs, R.; Eichkorn, K.; Treutler, O.; Marco, H.; Ahlrichs, R. h. d. o. h. d. d. o.---U., Auxiliary Basis Sets to Approximate Coulomb Potentials (Chem . Phys . Lett. 240 ( 1995 ) 283 ) * Auxiliary Basis Sets to Approximate Coulomb Potentials. Chem. Phys. Lett. 1995, 240 (September), 283-290.

(24) Treutler, O.; Ahlrichs, R., Efficient molecular numerical integration schemes. J. Chem. Phys. 1995, 102, 346-354.

(25) Yoshida, Z.; Johnson, S. G.; Kimura, T.; Krsul, J. R., Neptunium. In The Chemistry of the Actinide and Transactinide Elements, Morss, L. R.; Edelstein, N. M.; Fuger, J., Eds. Springer Netherlands: Dordrecht, 2006; pp 699-812.

(26) Rao, L.; Tian, G.; Teat, S. J., Complexation of $\mathrm{Np}(\mathrm{V})$ with N,N-dimethyl-3-oxa-glutaramic acid and related ligands: thermodynamics, optical properties and structural aspects. Dalton

Trans. 2010, 39, 3326-3330. 